\title{
Competitive Fitness of Phytophthora infestans Isolates Under Semiarid Field Conditions
}

\author{
J. S. Miller and D. A. Johnson
}

First author: University of Minnesota, Department of Plant Pathology, St. Paul 55108-6030; and second author: Washington State University, Department of Plant Pathology, Pullman 99164-6430.

Accepted for publication 12 November 1999.

\begin{abstract}
Miller, J. S., and Johnson, D. A. 2000. Competitive fitness of Phytophthora infestans isolates under semiarid field conditions. Phytopathology 90:220-227.

Spread of US-1 and US-8 isolates of Phytophthora infestans were observed in field plots of potato (cv. Russet Burbank) grown in Pullman, WA, in 1996 and 1997. Infected greenhouse-grown potato plants with similar lesion numbers for both strains were transplanted to field plots with four replications. Spread of the pathogen was favored by sprinkler irrigation during evening hours. Diseased leaves and stems were sampled over time to determine the spread of US-1 and US-8 isolates. In 1996, late blight developed in two of the four replications (105 and 87 total isolates recovered). From those two replications, two US-1 isolates were recovered, both from the same replication. Nine isolates from one replication and six isolates from another displayed a phenotype different from the initial isolates, as determined by compatibility type, allozyme genotype, and re-

striction fragment length polymorphism genotype. These putative recombinant isolates may have arisen from sexual recombination between the US- 1 and US-8 isolates. The remaining isolates were of the US-8 strain. In 1997, late blight developed in all four replications $(123,122,81$, and 34 total isolates recovered). One US-1 isolate was recovered (out of 123) from one replication and three (out of 122) from another, and the remaining isolates were of the US-8 strain. Isolates with phenotypes differing from the initial isolates were not recovered in 1997. In both years, oospores were not observed in the plant tissue examined. The low number of putative recombinant isolates in 1996 and their absence in 1997 suggests that sexual reproduction between US-8 and US-1 isolates in a field setting is a rare event. The predominance of US-8 isolates recovered is a measure of the increased fitness and aggressiveness of the US- 8 isolates relative to the US- 1 isolate used in this study. This further substantiates the increased aggressiveness of the US-8 genotype observed on excised tissues and potted plants in previous laboratory and greenhouse studies.
\end{abstract}

Serious yield losses are incurred on cultivated potatoes (Solanum tuberosum L.) as a result of late blight caused by the pathogen Phytophthora infestans (Mont.) de Bary. Late blight in the United States was first documented in 1843 (46). Phenotypic and genetic characterization of sample collections from around the world suggested that a single clonal lineage existed worldwide outside Mexico until the 1970s (17). This clonal lineage was characterized by the A1 compatibility type, sensitivity to the phenylamide fungicide metalaxyl, and a distinct allozyme genotype and restriction fragment length polymorphism (RFLP) genotype $(17,22,23)$. In recent decades, this clonal lineage has been replaced by new strains in Canada $(3,7,8,16,22,23)$, the United States $(7-9,16,22,23,35,36)$, the United Kingdom (40,48), Poland $(45,47)$, the Netherlands (10, 45), Germany (6), France (1), Israel (24), Ecuador (13), Korea (33), and Japan $(33,39,49)$. The presence of new strains may be partially responsible for the increased severity and occurrence of potato late blight epidemics in recent years (14).

New strains may be more fit or better competitors than is the old clonal lineage. Fitness is defined as the ability of an organism to contribute to the next gene pool and has been described as the progeny-to-parent ratio over a period of time (55). Fitness among isolates from the old clonal lineage was found to differ under field conditions (51). Fitness was estimated by calculating exponential and logistic growth rates for disease progress and population assessment data, respectively (51). These two methods differed in estimating the magnitude of isolate fitness but gave the same rela-

Corresponding author: J. S. Miller; E-mail address: jmiller@ puccini.crl.umn.edu

Publication no. P-2000-0124-04R

(C) 2000 The American Phytopathological Society tive ranking of the different isolates. Greater fitness differences were observed in conditions less favorable for pathogen spread than in conditions favorable for the pathogen. Fitness of isolates from the sexually reproducing population from Mexico was not found to be significantly different from fitness of isolates from the old clonal lineage in the United States when isolates were tested on potatoes in growth chambers (52). Fitness testing of metalaxyl-resistant and metalaxyl-sensitive isolates in Israel indicated that metalaxyl-resistant isolates caused larger lesions than did metalaxyl-sensitive isolates, but metalaxyl-sensitive isolates either did not differ significantly or had significantly higher sporulation capacity values than did metalaxyl-resistant isolates $(27,28,30)$. However, the compound fitness index, which was a product of infection frequency, lesion area, and sporulation capacity, was highest for metalaxylresistant isolates $(28,30)$. Tests done in the laboratory on isolates from the United States comparing new clonal lineages (US-6, US7, US-8, and US-11) with the old clonal lineage (US-1) indicate that the new lineages are more fit in terms of lesion expansion, latent period, lesion area, and sporulation capacity $(31,37)$.

Factors influencing competition in general between fungal pathogens include the relative ability to occupy host tissue, production of chemicals inhibitory to other pathogens, and changes in host resistance as a result of infection by another pathogen (2). Competition experiments using $P$. infestans have been done using metalaxyl-sensitive and metalaxyl-resistant isolates $(4,27,29)$ and oxadixyl-sensitive and oxadixyl-resistant isolates (5). In the studies cited above, mixtures of sensitive and resistant isolates were composed in a ratio of 9:1, respectively, and inoculated on potato plants. In the absence of the test chemical, isolates resistant to the test chemical were predominantly recovered when symptomatic tissues were sampled prior to complete defoliation, indicating that the resistant isolates had a competitive advantage over sensitive isolates. 
Sexual recombination between isolates of different compatibility types has been observed in areas where replacement of the old strain by new strains is occurring, such as British Columbia (22), Poland (47), and the Netherlands (11). In the case of British Columbia, recombination appears to have occurred between new strains with the A1 and A2 compatibility type, not between a new strain with the A2 compatibility type and the old US-1 strain (22). Sexual reproduction between the old US- 1 strain and the new US-8 strain has been demonstrated in vitro (12), but other evidence suggests that it may be unlikely in nature because of ploidy differences between the two strains $(15,45,53)$. An intraspecific post-zygotic mating barrier would help explain the apparent absence of recombination in areas where US- 8 and US-1 isolates have coexisted for some time.

The ability of isolates from new strains (i.e., US-8) to infect, grow, and sporulate at rates higher than those from US-1 isolates indicates that new strains may be able to spread within and among potato fields more quickly than is the US-1 strain. Epidemics caused by new strains may even progress fast enough to preclude the establishment of the US-1 strain. The primary purpose of this study was to compare the competitive fitness of $P$. infestans isolates from the old US-1 strain with the new US-8 strain in a field setting. A secondary objective was to evaluate the potential for sexual recombination between isolates representing the two strains in a field setting. This test was conducted at Pullman, WA, which is geographically isolated from commercial potato fields in Washington and Idaho, essentially eliminating the risk of inoculum contamination from external sources and the risk of providing inoculum for commercial potato farms.

\section{MATERIALS AND METHODS}

Inoculum production. Isolates of $P$. infestans used in this study were obtained from naturally infected foliage of potatoes grown commercially in the Columbia Basin of Washington between 1994 and 1996 (36). Isolates were maintained on rye extract agar in the dark at $18^{\circ} \mathrm{C}$. Strain designation was based on compatibility type, metalaxyl sensitivity, and allozyme genotype as described previously $(36,37)$. Ten US-1 isolates and twenty US-8 isolates from this collection were screened for aggressiveness by inoculating detached potato leaflets and measuring lesion expansion. The most aggressive US-1 (Fi 2, both years) and US-8 isolates (584 in 1996, CF1 in 1997), as determined by the highest area under the lesion expansion curve (AULEC) value (37), were chosen for field inoculations.

Two months prior to field plot inoculation, test isolates were inoculated on detached leaves and maintained in the laboratory. Sporangia from each isolate were harvested from detached leaves on a weekly basis and used to inoculate a new set of detached leaves. This cycle was repeated until the time of field plot inoculation. This procedure was effective in maintaining isolate aggressiveness, since all isolates treated in this manner remained infective and able to destroy detached leaves over the duration of the experiment. For field plot inoculation, each isolate was broadcast inoculated with the use of an atomizer (Sears, Roebuck and Co., Chicago, IL) on 10 8-week-old potato plants (cv. Russet Burbank) grown in a greenhouse. Inoculated potted plants were placed in a mist chamber where free water was maintained on leaf and stem surfaces for $24 \mathrm{~h}$ to promote infection. Plants were then incubated on a greenhouse bench for 5 days. Inoculated plants were then selected for transplanting to the field based on the number of leaf and stem lesions (Table 1). For each field replication, transplants were chosen so that similar lesion numbers or similar lesion areas of both US-8 and US-1 strains were present. For some replications, plants inoculated with the US- 8 isolate had more stem lesions than did US-1-infected plants. In these cases, a number of infected leaflets were removed from US-8-infected plants prior to transplanting so that the total lesion number on both US-1- and US-8-infected transplants in each replication was equal.
Certified 'Russet Burbank' potato seed was planted on 24 May 1996 and 13 May 1997 in Pullman, WA, at the Horticultural Research Farm. Plant spacing was $23 \mathrm{~cm}$ within rows and $86 \mathrm{~cm}$ between rows. Preplant fertilization was applied at a rate of $112 \mathrm{~kg}$ of 20/20/20 NPK per ha in 1996 and $146 \mathrm{~kg}$ of 20/20/20 NPK per ha in 1997. Preplant herbicide (EPTC [Eptam 7E], 4.1 liters/ha) was applied both years. Irrigation by solid-set overhead sprinklers was used to supplement natural rainfall. Infected greenhouse-grown plants were transplanted to the field on 18 August 1996 and 16 July 1997. The US-1- and US-8-infected plants for each replication were transplanted in the center of each replication $30 \mathrm{~cm}$ from each other. Immediately after transplanting infected plants, supplemental irrigation was applied for $20 \mathrm{~min}$ at 2-h intervals from 10:00 p.m. until 8:00 a.m. During this time, lesions of both US-1 and US-8 transplants were observed to be sporulating. Subsequent supplemental irrigation was applied twice weekly, with sprinklers operating for $2 \mathrm{~h}$ in the late evening and $2 \mathrm{~h}$ in the early morning the following day. The experiment encompassed 30 rows, $33.5 \mathrm{~m}$ in length. Each replication was an unsprayed corner of the field, 12 rows wide and $9 \mathrm{~m}$ long. The potato plants growing in the area separating the replications were treated weekly either with chlorothalonil, mancozeb, or metiram. Pullman is approximately 100 miles from the nearest commercial potato production area, which reduces the risk of inoculum contamination from external sources and the risk of providing inoculum for commercial potato farms. Potatoes and tomatoes in a few home gardens near the experimental plot were monitored for the presence of late blight in an effort to estimate the potential of these two risks. Transplants remained viable for approximately 1 month from the date of transplanting in both years.

Plots were scouted twice weekly after transplanting. Scouting was done only when the plot was dry in the afternoon hours (between 1:00 and 6:00 p.m.) to minimize the risk of pathogen spread during the scouting procedure. When a stem or leaf lesion (or group of lesions) was found, the location was marked with a labeled metalwire flag. As the epidemic progressed, the number of lesions selected for characterization was based subjectively on disease intensity (more lesions were sampled in plot regions where disease was more severe). For the first three sample dates, one lesion was taken for approximately every 5 to 10 lesions observed. A smaller proportion of lesions was sampled (approximately 1 for every 20 lesions) for the remainder of the sample dates. At each sampling date, isolates were taken from all locations within replications based on the estimated number of lesions in an area. Only new lesions (leaflet lesions covering about $1 / 4$ of the leaflet surface and stem lesions less than $3 \mathrm{~cm}$ long) were selected at each sampling date. Leaves and stem sections with lesions were cut from the plant, placed in a plastic bag, and then taken directly to the laboratory

TABLE 1. Number of Phytophthora infestans leaf and stem lesions on greenhouse-grown plants that were transplanted to potato field plots a

\begin{tabular}{lrrrr}
\hline \multirow{2}{*}{$\begin{array}{l}\text { Year/ } \\
\text { isolate/lesion }\end{array}$} & \multicolumn{4}{c}{ Number of lesions } \\
\cline { 2 - 5 } 1996 & Replication 1 & Replication 2 & Replication 3 & Replication 4 \\
Fi 2 (US-1) & 24 & 30 & 26 & 28 \\
$\quad$ Stem & 1 & 3 & 2 & 2 \\
Leaf & 23 & 27 & 24 & 26 \\
584 (US-8) & 24 & 30 & 26 & 28 \\
Stem & 5 & 4 & 4 & 3 \\
Leaf & 19 & 26 & 22 & 25 \\
1997 & & & & 11 \\
Fi 2 (US-1) & 9 & 2 & 11 & 2 \\
Stem & 3 & 6 & 9 & 9 \\
Leaf & 6 & 6 & 10 & 2 \\
CF1 (US-8) & 9 & 2 & 1 & 7 \\
Stem & 4 & 4 & 9 & 9 \\
Leaf & 5 & & & \\
\hline
\end{tabular}

${ }^{\text {a }}$ Plants were inoculated and incubated in a greenhouse for 5 days. 
for isolation. Leaves and stems of hairy nightshade (Solanum sarrachoides Sendtner) showing late blight symptoms were also sampled. A subset of randomly selected lesions was retained in fixative solution (90:5:5 [ $\mathrm{vol} / \mathrm{vol} / \mathrm{vol}]$ ethanol/glacial acetic acid/ formalin) and examined for the presence of oospores. The fixative solution cleared the lesions, making it easier to see potential oospores. Stem lesions were thinly sliced (about $1 \mathrm{~mm}$ thick) with a razor blade, mounted on a microscope slide with water, and examined under a light microscope. Leaflet lesions were placed directly on the slide.

Infected stems and leaves were placed in glass petri dishes $(15 \times$ $100 \mathrm{~mm}$ ) containing moistened filter paper and incubated at $18^{\circ} \mathrm{C}$ with a light intensity of 57 to $59 \mu \mathrm{mol} \mathrm{m} \mathrm{m}^{-2} \mathrm{~s}^{-1}$ overnight to promote sporulation. Sporangia from sporulating lesions were transferred from lesions to rye extract agar using a sterilized $3-\mathrm{mm}^{2}$ moistened filter paper square. Once an initial culture was established on rye extract agar, isolates were derived by transferring three single zoosporangia to a new rye extract agar plate. After colonies were established from these zoosporangia, an isolate was established by transferring a mycelial plug from the growing edge of one of the three single zoosporangia-derived colonies. Transfers were made before the three colonies grew together. Isolates were maintained on rye extract agar and stored at $18^{\circ} \mathrm{C}$ in darkness. Compatibility types were determined as described previously (36) and glucose-6-phosphate isomerase ( $\mathrm{Gpi}$ ) and peptidase (Pep) allozyme phenotypes were determined $(21,36)$.

Some isolates in 1996 appeared to be sexual recombinants, characterized by the A1 compatibility type (US-1) and the Gpi 100/111/122 and Pep 100/100 allozyme phenotype (US-8). RFLP genotype as revealed by the RG57 nuclear DNA probe was determined (19) for the putative recombinant isolates in 1996 and for

TABLE 2. Number of US-1, US-8, and nonparental phenotype isolates of Phytophthora infestans recovered from field plots after transplanting potato plants infected with either US-1 or US-8 isolates in the center of each plot ${ }^{\mathrm{a}}$

\begin{tabular}{lcccc}
\hline Year/plot $^{\mathrm{b}}$ & US-1 & $\begin{array}{c}\text { Nonparental } \\
\text { phenotypes }^{\mathrm{c}}\end{array}$ & US-8 & $\begin{array}{c}\text { Total isolates } \\
\text { recovered }\end{array}$ \\
\hline 1996 & & & & \\
Plot 2 & 2 & 9 & 94 & 105 \\
Plot 3 & 0 & 6 & 81 & 87 \\
1997 & & 0 & 122 & 123 \\
Plot 1 & 1 & 0 & 119 & 122 \\
Plot 2 & 3 & 0 & 81 & 81 \\
Plot 3 & 0 & 0 & 34 & 34 \\
Plot 4 & 0 & 15 & 531 & 552 \\
Total & 6 & 0
\end{tabular}

${ }^{a}$ Recovered isolates were characterized for compatibility type and allozyme genotype (glucose-6-phosphate isomerase [Gpi] and peptidase [Pep]).

b Plot designation refers to the replication (1 through 4). Disease in replications 1 and 4 did not develop in 1996.

${ }^{c}$ Nonparental phenotypes were characterized by the A1 compatibility type (characteristic of US-1) and the Gpi 100/111/122, Pep 100/100 genotype (characteristic of US-8).

TABLE 3. Characteristics of Phytophthora infestans isolates used to initiate late blight epidemics in field plots and characteristics of isolates recovered from these plots during the epidemics in 1996 and 1997

\begin{tabular}{lccrc}
\hline Isolate & $\begin{array}{c}\text { Compatibility } \\
\text { type }\end{array}$ & $\begin{array}{c}\text { Gpi } \\
\text { genotype }^{\mathrm{a}}\end{array}$ & $\begin{array}{c}\text { Pep } \\
\text { genotype }^{\mathrm{b}}\end{array}$ & $\begin{array}{c}\text { RFLP } \\
\text { genotype }^{\mathrm{c}}\end{array}$ \\
\hline CF1 & A2 & $100 / 111 / 122$ & $100 / 100$ & 1001100001001101000110111 \\
584 & A2 & $100 / 111 / 122$ & $100 / 100$ & 1001100001001101000110111 \\
Fi 2 & A1 & $86 / 100$ & $92 / 100$ & 1011101011001101000110011 \\
PR $^{\text {d }}$ & A1 & $100 / 111 / 122$ & $100 / 100$ & 1001100001001101000110111 \\
\hline
\end{tabular}

a Glucose-6-phosphate isomerase phenotype.

${ }^{\mathrm{b}}$ Peptidase phenotype.

${ }^{c}$ Restriction fragment length polymorphism (RFLP) genotype revealed by the RG57 probe (19). Presence or absence of a band is denoted by a 1 or 0 , respectively.

${ }^{d}$ Putative recombinant isolates found in 1996. randomly selected isolates in 1997 (putative recombinant isolates were not detected in 1997).

\section{RESULTS}

A total of 192 isolates was recovered in 1996 (Table 2). Late blight in two replications was primarily caused by the US-8 strain (91\% of all isolates). Only two US-1 isolates (1\% of all isolates) were recovered in 1996. Six isolates (3\%) were obtained from hairy nightshade (three from each replication). Fifteen isolates $(8 \%)$ had a phenotype different from either of the original isolates used to inoculate the field plot. These isolates were characterized by the A1 compatibility type and the Gpi 100/111/122 and Pep 100/100 phenotype (Table 3). The RFLP genotype for these isolates was typical of the US-8 genotype (Fig. 1). Six of these fifteen isolates (four from replication 2 and two from replication 3) were found when isolates were being established from single sporangia. On these six occasions, numerous oospores were formed between colonies originating from sporangia derived from the same lesion. The A2 compatibility type colonies were identified as US-8 isolates (Gpi 100/111/122, Pep 100/100). The A1 colonies were identical for allozyme and RFLP genotypes. The A1 compatibility type proved stable throughout time in culture, and these isolates consistently produced numerous oospores when paired with an A2 compatibility type tester isolate and never produced oospores when paired with an A1 compatibility type tester. These six A1 colonies were grouped with the other isolates designated as putative recombinants, since they were similar for all characteristics measured in this test.

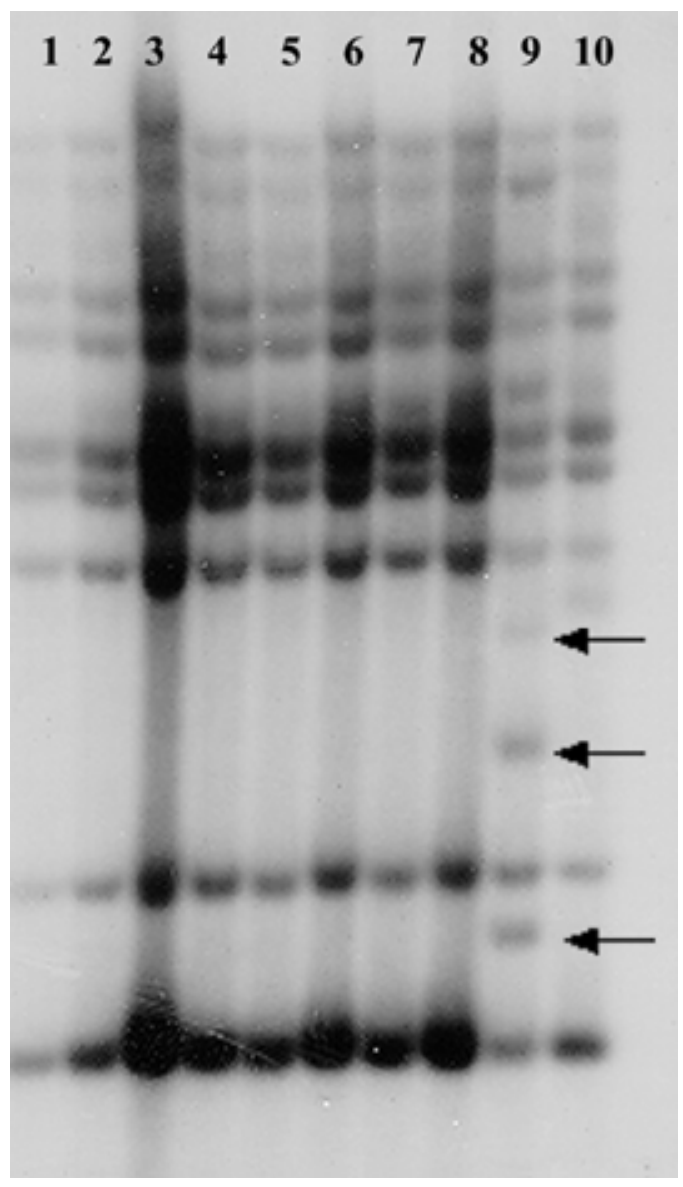

Fig. 1. DNA fingerprint generated using the RG57 probe. Lanes 2 and 9 represent the initial US-8 and US-1 isolates, respectively, released into field plots during 1996. Lanes 1, 3 to 8, and 10 represent isolates recovered from experimental plots that had the A1 mating type and an allozyme phenotype typical of the US-8 genotype (Gpi 100/111/122, Pep 100/100). Arrows refer to RG57 bands 3, 7, and 9 that are present in the US-1 genotype, but not in US-8. 
In 1997, four US-1 isolates (1\% of the total) were recovered out of 360 total isolates (Table 2). Isolates with phenotypes different from either of the initial isolates used to inoculate the field plot were not found in 1997. All isolates in 1997 that were analyzed for RFLP genotype had genotype patterns typical of the US-8 strain. Hairy nightshade plants infected with $P$. infestans were not found. In both 1996 and 1997, late blight was not found in home gardens in Pullman.

Late blight lesions in 1996 were first found on 16 September, approximately 4 weeks after infected transplants were placed in the field. At this time, most isolates were found within $1 \mathrm{~m}$ of the plot center (Fig. 2). Isolates were not found beyond $5 \mathrm{~m}$ until almost 3 weeks (5 October) after the first sample date (16 September). In 1997, late blight lesions were found 12 days (28 July) after transplanting infected plants (16 July). When lesions were first found, they were all within $1 \mathrm{~m}$ of the plot center (Fig. 3). Isolates were not found beyond $5 \mathrm{~m}$ until 3 weeks later (14 August). In both years, most isolates were found progressively farther from the plot center at each sample date. In 1996, potato plants began to senesce in early October. By 15 October, the pathogen appeared to stop spreading. Most isolates were detected in the 2- to <4-m range at this time. US- 1 isolates were found in the 1- to <2-m range on the first sample date, and then not detected again until the third sample date in the $2-$ to $<3-\mathrm{m}$ range. Putative recombinant isolates were found in the 0 - to $<2-\mathrm{m}$ range on the first two sample dates and then in the 2- to $<3-\mathrm{m}$ and 3- to $<4-\mathrm{m}$ ranges on 11 and 15 October, respectively. In 1997, US-1 isolates were found in the 0 - to $<1-\mathrm{m}$ and 3- to <4-m ranges on the second sample date and in the 1- to $<2$-m range on the third sample date. Only US-8 isolates were detected after that time.

\section{DISCUSSION}

This study shows that the two US- 8 isolates used in this experiment were more fit than was the US-1 isolate under irrigated, semiarid conditions. In both 1996 and 1997, US-8 isolates predominated. Only a few US-1 isolates were recovered both years. Other studies using $P$. infestans have shown that, when two isolates are coinoculated on a susceptible host, one of the isolates establishes itself at the expense of the other. Thurston (50) observed that, when mixtures of different races of $P$. infestans were coinoculated in a greenhouse using a sporangial suspension, one race was recovered predominantly over the other. Studies done in Israel showed that isolates of $P$. infestans resistant to either metalaxyl or oxadixyl were predominantly reisolated from potatoes in the absence of the test chemical, even though they composed only $10 \%$ of the initial inoculum $(4,5,27,29)$. Additionally, when a potato-aggressive isolate (US-1) of $P$. infestans was inoculated in the field with a tomato-aggressive isolate (US-6), US-1 isolates were predominantly recovered at the expense of the US-6 isolates on po-
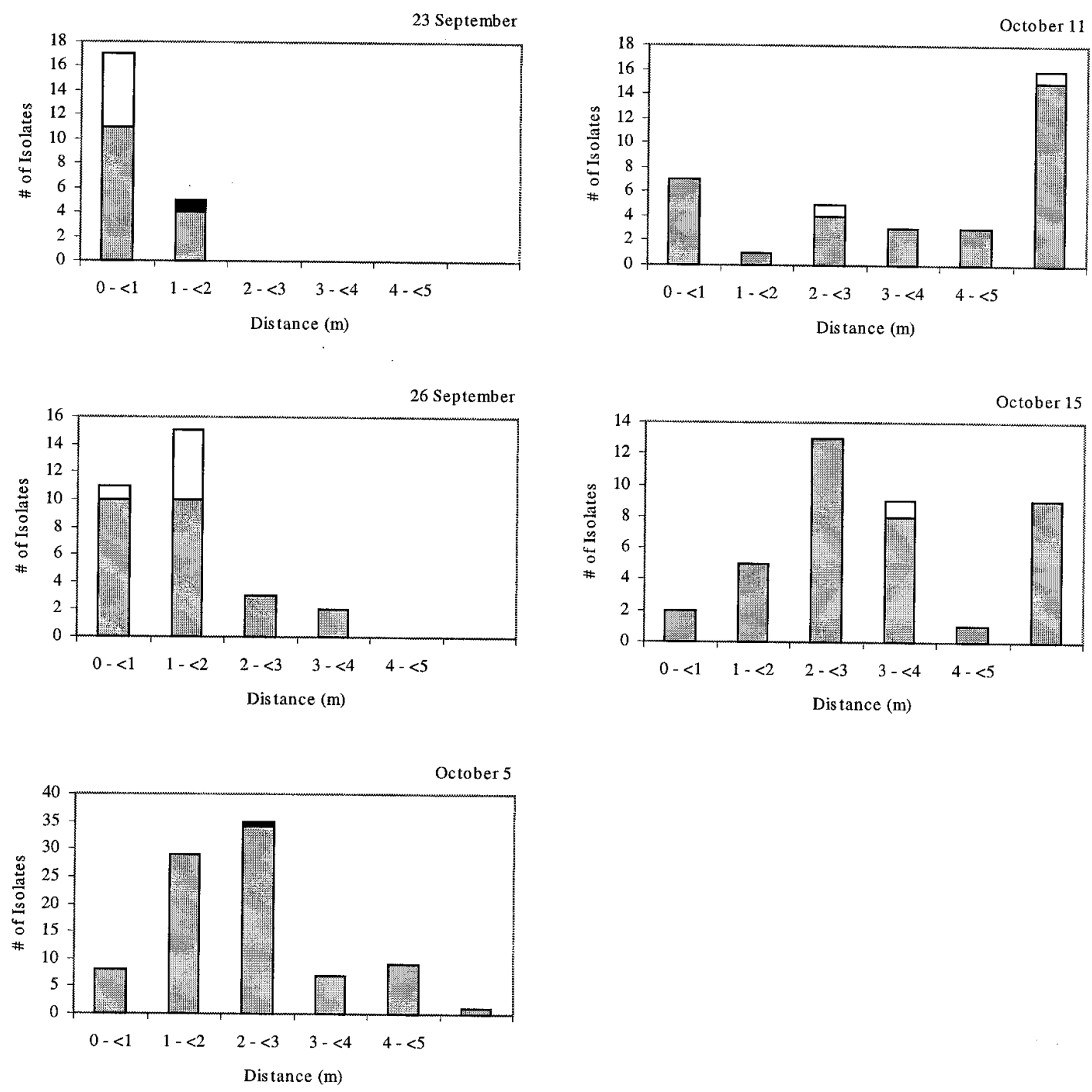

Fig. 2. Distance of spread from plot center for isolates of Phytophthora infestans recovered in 1996 when infected plants were transplanted near the plot center (gray $=$ US-8, black $=$ US-1, and white $=$ nonparental phenotypes). Infected plants were transplanted to the field on 18 August. 
tato plants (34). On tomato, the reverse was true, only no US-1 isolates were recovered at all. Our test differed slightly from previous tests in the method of inoculation, since both US-1infected and US-8-infected plants were transplanted into the field plots. The potential existed for sporangia of each genotype to be disseminated independent of the other genotype. Despite this possibility, the results of our tests support the idea that a single strain will establish itself at the expense of other strains. Differences in sporulation between US- 1 and US-8 isolates in laboratory and greenhouse studies were often slight $(31,37)$. However, differences in lesion expansion were often significant. Computer simulations predicted that fungicide applications every 7 days during an epidemic caused by the US-8 strain would give control similar to fungicide applications every 9 to 10 days during an epi- demic caused by the US-1 strain (31). This is the first published report to demonstrate differential fitness of two strains in a field setting.

Sterile filtrate from germinating sporangia has been observed to inhibit germination of other sporangia (50). Inhibition by the filtrate was generally nonspecific, affecting the race from which the filtrate was derived as much as other races. In our experiments, both US-1- and US-8-infected transplants were sporulating after supplemental irrigation, so the potential for both genotypes to spread existed. If sporangia from the US-8 strain germinated faster than did the US-1 sporangia, then germination of the US-1 sporangia could have been partially inhibited, allowing US-8 to infect with greater frequency than could US-1. This would explain the scarcity of US-1 isolates recovered both years.
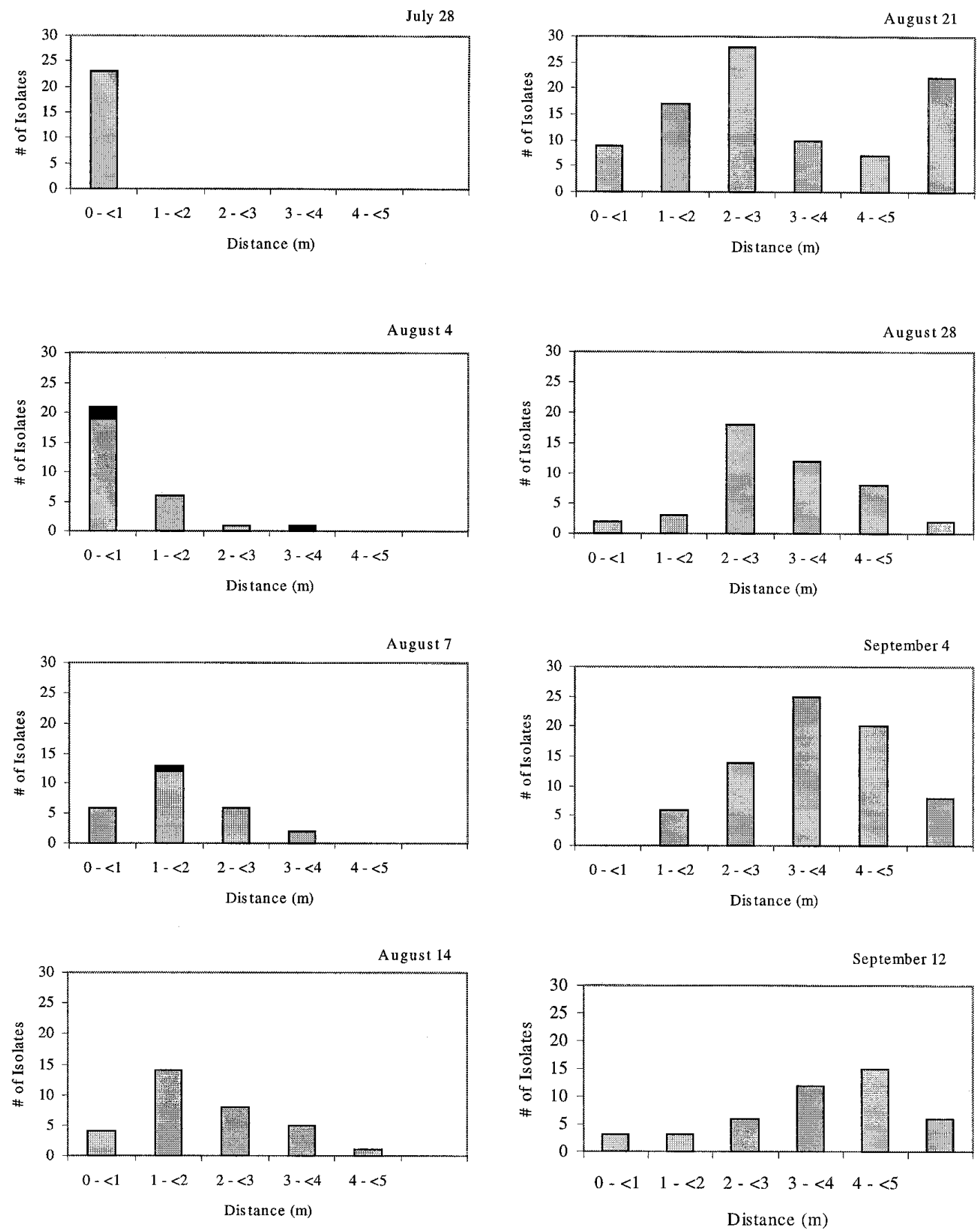

Fig. 3. Distance of spread from plot center for isolates of Phytophthora infestans recovered in 1997 when infected plants were transplanted near the plot center (gray = US-8 and black = US-1). Infected plants were transplanted to the field on 16 July. 
The recovery of isolates with an allozyme genotype and RFLP genotype similar to the US-8 isolate used for inoculating field plots but having the A1 compatibility type (characteristic of the US-1 isolate used to inoculate the field plot) suggests sexual reproduction may have occurred between the US- 8 and US- 1 isolates in the field. Sexual recombination could have occurred early in the epidemic, and all of the putative recombinants could have descended asexually from a single oospore. Oospores were not found in lesion tissue, but the amount of infected plant tissue examined was relatively small. Previous genetic analysis of $P$. infestans has shown that pairing an isolate presumably from the old US-1 lineage and an A2 isolate can lead to progeny that show segregation for $G p i$ alleles (42) and for compatibility type (43). The US-1 parent could have contributed the A1 compatibility type and Gpi 100 allele, which is common to both US- 1 and US-8. The US- 8 and US- 1 RFLP genotypes differ by 4 bands (bands 3, 7, 9, and 25) out of 25 . Evidence of sexual recombination in this study was not observed based on the RFLP genotype. The four polymorphic markers may be located close together on the same chromosome or may be located on a few chromosomes. Thus, the consequences of recombination would not have been detected with RFLP fingerprinting. Additionally, the absence of the Gpi 86 allele and the lack of segregation for the four polymorphic RFLP bands may have occurred by chance during meioses.

Evidence does exist for meiotic nondisjunction in Phytophthora (20). Nondisjunction of the Gpi allozyme locus from the A2 parent could account for A1 isolates with the Gpi 100/111/122 genotype. In a survey of isolates from a sexually reproducing population of $P$. infestans in the Netherlands, two pairs of A1 and A2 isolates were found with identical Gpi, Pep, and RFLP genotypes $(18,47)$. It is possible that the A2 isolates in these pairs resulted from a recombination event in which meiotic nondisjunction occurred.

While sexual reproduction between new strains (US-8) and the old strain (US-1) has been demonstrated in the laboratory (12), contact between the two strains in nature may result in incompatible mating because of differences in ploidy level $(15,45,53)$. The fact that putative recombinant isolates were only recovered in 1 year, and then only comprised a small proportion of all isolates recovered (8\% in 1996), suggests that sexual reproduction between US-8 and US-1 isolates is rare. An alternative explanation for the putative recombinant isolates is that they did not arise from sexual recombination between US-8 and US-1 isolates, but resulted from self fertilization. Selfing in heterothallic Phytophthora species can be induced interspecifically, intraspecifically, by other fungi such as Trichoderma (32), and by fungicides (54). In studies using $P$. parasitica, oospores appeared to primarily result from intraspecific induced selfing, rather than from cross fertilization (32). Progeny from these oospores had parental traits for antibiotic resistance but exhibited an apparent compatibility type change. In crosses using $P$. infestans, most of the progeny resulted from true hybridization, but some selfing was evident $(43,44)$. Shattock et al. (41) reported that some of the progeny derived from a selfed A1 isolate showed segregation for allozyme alleles, while other progeny did not. In their test, segregation of compatibility type was not observed, but only 10 isolates were examined. Selfing of $P$. infestans induced by $P$. drechsleri (separated by a polycarbonate membrane) gave some progeny that segregated for peptidase alleles and some that did not (44). In another study, induced selfing of an A2 isolate did result in A1 compatibility type progeny (20). The putative recombinant isolates recovered in our study could have arisen from the selfing of a US- 8 isolate induced by a US-1 isolate nearby. Subsequent oospore germination and asexual reproduction could have produced A1 compatibility type isolates with allozyme phenotypes and RFLP genotypes similar to the "parent."

Since this experiment was conducted in a field plot, the possibility exists that the putative recombinant isolates were not truly recombinant isolates, but rather the result of plot contamination. However, this explanation is unlikely. Disease did not develop in two replications in 1996. These replications were unsprayed and no lesions were observed prior to vine senescence. This indicates that contamination did not occur from an external source and that pathogen spread in the two infested replications was highly localized. Late blight was not found in home gardens, and no other potato field plots were present in the area. Additionally, in 1996, no isolates matching the phenotype of the putative recombinants were detected in the Columbia Basin of Washington and Oregon. All isolates characterized from commercial fields in the Basin in 1996 had the A2 mating type (J. S. Miller and D. A. Johnson, unpublished data). Fitness assessments can be confounded by interplot contamination (34), but this was not apparent in our plots in 1996. The two replications were on opposing corners of the field plot, and, as pointed out previously, contamination was not observed in the two replications where disease did not develop.

$P$. infestans spread from potato to hairy nightshade plants in our study in 1996. Control of nightshade in potato fields is important in relation to control of late blight. Hairy nightshade can remain alive long after potato plants have started to senesce and can act as a host for $P$. infestans. Late blight lesions on nightshade could serve as a source of inoculum that could infect tubers as they are lifted from the ground at harvest. In our plots, some nightshade plants still flourished after the potato foliage had completely senesced. Weed control in our plots (including nightshade) was much more efficient in 1997 than in 1996. As a result, infected nightshade plants were not found in 1997.

The number of new isolates harvested at each sample date was indicative of the amount of disease in that area of the field, so as late blight became more severe, more isolates were harvested from that area of the plot. Fewer isolates were taken from the field plot in 1996 because the epidemic started near the end of the season. The transplants were placed in the field in mid-August, but the pathogen did not spread and increase to detectable levels until almost 4 weeks later. This coincided with the death of the transplants. The time difference between transplanting and detection of pathogen spread most likely resulted from the hot, dry weather that prevailed during this time. The average daily maximum temperature during the interval from transplanting to detection in 1996 was $29^{\circ} \mathrm{C}$. The disease gradient was steep early in the season but leveled out as the season progressed, indicating gradual spread in the small plots. The pathogen spread from the center of the plot in a wavelike manner. Previous studies examining the spread of $P$. infestans under field conditions have shown similar results $(25,38,56)$.

Spread of the US-8 isolates was more efficient than was spread of the US-1 isolate in both years of the study. All isolates used in this test are capable of causing severe disease symptoms in the greenhouse. The US-8 isolates, however, were better competitors since they were able to establish themselves and spread in the field extensively, while the US-1 isolate spread very little. The US-1 isolate was capable of causing severe epidemics but, in competition with the US-8 isolates, it was much less fit. The US-1 strain may be less fit because of the buildup of deleterious alleles or as a result of a population bottleneck (15). This may be one reason why the US-8 strain has replaced the US- 1 strain in many potato-growing areas of the United States. Because the US- 8 strain is a better competitor, more fungicide applications are needed to control late blight epidemics caused by the US- 8 strain than by the US- 1 strain (26,31).

\section{ACKNOWLEDGMENTS}

Plant Pathology New Series 0280, Department of Plant Pathology, College of Agriculture and Home Economics Research Center, Project No. 0678, Washington State University, Pullman 99164-6430. We thank the Washington Potato Commission for funding a portion of this research. We thank W. E. Fry for his helpful insights on the results, W. E. Fry and C. Smart for aid in RFLP analysis, R. Alldredge for advice on the statistical 
analysis, and T. Cummings and D. Vargas for technical assistance. We also thank L. M. Carris, G. S. Campbell, and R. E. Thornton for their critical review of the manuscript.

\section{LITERATURE CITED}

1. Andrivon, D., Béasse, C., and Laurent, C. 1994. Characterization of isolates of Phytophthora infestans collected in northwestern France from 1988 to 1992. Plant Pathol. 43:471-478.

2. Campbell, C. L., and Madden, L. V. 1990. Introduction to Plant Disease Epidemiology. John Wiley \& Sons, New York.

3. Chycoski, C. I., and Punja, Z. K. 1996. Characteristics of populations of Phytophthora infestans from potato in British Columbia and other regions of Canada during 1993 to 1995. Plant Dis. 80:579-589.

4. Cohen, Y., Kadish, D., and Grinberger, M. 1987. Competitive and noncompetitive fitness of Phytophthora infestans resistant and sensitive to metalaxyl. (Abstr.) Phytopathology 77:1729.

5. Cohen, Y., and Samoucha, Y. 1990. Competition between oxadixyl-sensitive and -resistant field isolates of Phytophthora infestans on fungicide treated potato crops. Crop Prot. 9:15-20.

6. Daggett, S. S., Götz, E., and Therrien, C. D. 1993. Phenotypic changes in populations of Phytophthora infestans from eastern Germany. Phytopathology 83:319-323.

7. Deahl, K. L., DeMuth, S. P., Sinden, S. L., and Rivera-Peña, A. 1995. Identification of mating types and metalaxyl resistance in North American populations of Phytophthora infestans. Am. Potato J. 72:35-49.

8. Deahl, K. L., Goth, R. W., Young, R., Sinden, S. L., and Gallegly, M. E. 1991. Occurrence of the A2 mating type of Phytophthora infestans in potato fields in the United States and Canada. Am. Potato J. 68:717-725.

9. Deahl, K. L., Inglis, D. A., and DeMuth, S. P. 1993. Testing for resistance to metalaxyl in Phytophthora infestans isolates from northwestern Washington. Am. Potato J. 70:779-795.

10. Drenth, A., Goodwin, S. B., Fry, W. E., and Davidse, L. C. 1993. Genotypic diversity of Phytophthora infestans in the Netherlands revealed by DNA polymorphisms. Phytopathology 83:1087-1092.

11. Drenth, A., Janssen, E. M., and Govers, F. 1995. Formation and survival of oospores of Phytophthora infestans under natural conditions. Plant Pathol. 44:86-94.

12. Fay, J. C., and Fry, W. E. 1997. Effects of hot and cold temperatures on the survival of oospores produced by United States strains of Phytophthora infestans. Am. Potato J. 74:315-323.

13. Forbes, G. A., Escobar, X. C., Ayala, C. C., Revelo, J., Ordoñez, M. E., Fry, B. A., Doucett, K., and Fry, W. E. 1997. Population genetic structure of Phytophthora infestans in Ecuador. Phytopathology 87:375-380.

14. Fry, W. E., and Goodwin, S. B. 1997. Resurgence of the Irish potato famine fungus. Bioscience 47:363-371.

15. Goodwin, S. B. 1997. The population genetics of Phytophthora. Phytopathology 87:462-473.

16. Goodwin, S. B., Cohen, B. A., Deahl, K. L., and Fry, W. E. 1994. Migration from northern Mexico as the probable cause of recent genetic changes in populations of Phytophthora infestans in the United States and Canada. Phytopathology 84:553-558.

17. Goodwin, S. B., Cohen, B. A., and Fry, W. E. 1994. Panglobal distribution of a single clonal lineage of the Irish potato famine fungus. Proc. Natl. Acad. Sci. U.S.A. 91:11591-11595.

18. Goodwin, S. B., and Drenth, A. 1997. Origin of the A2 mating type of Phytophthora infestans outside Mexico. Phytopathology 87:992-999.

19. Goodwin, S. B., Drenth, A., and Fry, W. E. 1992. Cloning and genetic analyses of two highly polymorphic, moderately repetitive nuclear DNAs from Phytophthora infestans. Curr. Genet. 22:107-115.

20. Goodwin, S. B., and Fry, W. E. 1994. Genetic analysis of interspecific hybrids between Phytophthora infestans and Phytophthora mirabilis. Exp. Mycol. 18:20-32.

21. Goodwin, S. B., Schneider, R. E., and Fry, W. E. 1995. Use of celluloseacetate electrophoresis for rapid identification of allozyme genotypes of Phytophthora infestans. Plant Dis. 79:1181-1185.

22. Goodwin, S. B., Sujkowski, L. S., Dyer, A. T., Fry, B. A., and Fry, W. E. 1995. Direct detection of gene flow and probable sexual reproduction of Phytophthora infestans in northern North America. Phytopathology 85: 473-479.

23. Goodwin, S. B., Sujkowski, L. S., and Fry, W. E. 1996. Widespread distribution and probable origin of resistance to metalaxyl in clonal genotypes of Phytophthora infestans in the United States and western Canada. Phytopathology 86:793-800.

24. Grinberger, M., Kadish, D., and Cohen, Y. 1989. Occurrence of the A2 mating type and oospores of Phytophthora infestans in potato crops in Israel. Phytoparasitica 17:197-204.

25. Hirst, J. M., and Stedman, O. J. 1960. The epidemiology of Phytophthora infestans. II. The source of inoculum. Ann. Appl. Biol. 48:
489-517

26. Johnson, D. A., Cummings, T. F., Hamm, P. B., Rowe, R. C., Miller, J. S., Thornton, R. E., Pelter, G. Q., and Sorensen, E. J. 1997. Potato late blight in the Columbia Basin: An economic analysis of the 1995 epidemic. Plant Dis. 81:103-106.

27. Kadish, D., and Cohen, Y. 1988. Competition between metalaxyl-sensitive and metalaxyl-resistant isolates of Phytophthora infestans in the absence of metalaxyl. Plant Pathol. 37:558-564.

28. Kadish, D., and Cohen, Y. 1988. Fitness of Phytophthora infestans isolates from metalaxyl-sensitive and -resistant populations. Phytopathology 78:912-915

29. Kadish, D., and Cohen, Y. 1989. Population dynamics of metalaxylsensitive and metalaxyl-resistant isolates of Phytophthora infestans in untreated crops of potato. Plant Pathol. 38:271-276.

30. Kadish, D., Grinberger, M., and Cohen, Y. 1990. Fitness of metalaxylsensitive and metalaxyl-resistant isolates of Phytophthora infestans on susceptible and resistant potato cultivars. Phytopathology 80:200-205.

31. Kato, M., Mizubuti, E. S., Goodwin, S. B., and Fry, W. E. 1997. Sensitivity to protectant fungicides and pathogenic fitness of clonal lineages of Phytophthora infestans in the United States. Phytopathology 87:973-978.

32. Ko, W. 1988. Hormonal heterothallism and homothallism in Phytophthora. Annu. Rev. Phytopathol. 26:57-73.

33. Koh, Y. J., Goodwin, S. B., Dyer, A. T., Cohen, B. A., Ogoshi, A., Sato, N., and Fry, W. E. 1994. Migrations and displacements of Phytophthora infestans populations in East Asian countries. Phytopathology 84:922-927.

34. Legard, D. E., and Fry, W. E. 1996. Evaluation of field experiments by direct allozyme analysis of late blight lesions caused by Phytophthora infestans. Mycologia 88:608-612.

35. Marshall-Farrar, K. D., McGrath, M., James, R. V., and Stevenson, W. R. 1998. Characterization of Phytophthora infestans in Wisconsin from 1993 to 1995 . Plant Dis. 82:434-436.

36. Miller, J. S., Hamm, P. B., and Johnson, D. A. 1997. Characterization of the Phytophthora infestans population in the Columbia Basin of Oregon and Washington from 1992 to 1995. Phytopathology 87:656-660.

37. Miller, J. S., Johnson, D. A., and Hamm, P. B. 1998. Aggressiveness of isolates of Phytophthora infestans from the Columbia Basin of Washington and Oregon. Phytopathology 88:190-197.

38. Minogue, K. P., and Fry, W. E. 1983. Models for the spread of plant disease: Some experimental results. Phytopathology 73:1173-1176.

39. Mosa, A. A., Kato, M., Sato, N., Kobayashi, K., and Ogoshi, A. 1989. Occurrence of the A2 mating type of Phytophthora infestans on potato in Japan. Ann. Phytopathol. Soc. Jpn. 55:615-620.

40. Shattock, R. C., Shaw, D. S., Fyfe, A. M., Dunn, F. R., Loney, K. H., and Shattock, J. A. 1990. Phenotypes of Phytophthora infestans collected in England and Wales from 1985 to 1988: Mating type, response to metalaxyl and isozyme analysis. Plant Pathol. 39:242-248.

41. Shattock, R. C., Tooley, P. W., and Fry, W. E. 1986. Genetics of Phytophthora infestans: Characterization of single-oospore cultures from A1 isolates induced to self by intraspecific stimulation. Phytopathology 76 : 407-410.

42. Shattock, R. C., Tooley, P. W., Sweigard, J., and Fry, W. E. 1987. Genetic studies of Phytophthora infestans. Pages 175-185 in: Genetics and Plant Pathogenesis. P. R. Day and G. J. Ellis, eds. Blackwell Scientific, Oxford.

43. Shaw, D. S. 1987. The breeding system of Phytophthora infestans: The role of the A2 mating type. Pages 161-174 in: Genetics and Plant Pathogenesis. P. R. Day and G. J. Ellis, eds. Blackwell Scientific, Oxford.

44. Shaw, D. S. 1991. Genetics. Pages 131-170 in: Phytophthora infestans, the Cause of Potato Late Blight. Advances in Plant Pathology. Vol. 7. D. S. Ingram and P. H. Williams, eds. Academic Press, London.

45. Spielman, L. J., Drenth, A., Davidse, L. C., Sujkowski, L. J., Gu, W., Tooley, P. W., and Fry, W. E. 1991. A second world wide migration and population displacement of Phytophthora infestans? Plant Pathol. 40: 422-430.

46. Stevens, N. E. 1933. The dark ages in plant pathology in America: 18301870. J. Wash. Acad. Sci. 23:435-446.

47. Sujkowski, L. S., Goodwin, S. B., Dyer, A. T., and Fry, W. E. 1994. Increased genotypic diversity via migration and possible occurrence of sexual reproduction of Phytophthora infestans in Poland. Phytopathology 84:201-207.

48. Tantius, P. H., Fyfe, A. M., Shaw, D. S., and Shattock, R. C. 1986. Occurrence of the A2 mating type and self-fertile isolates of Phytophthora infestans in England and Wales. Plant Pathol. 35:578-581.

49. Therrien, C. D., Tooley, P. W., Spielman, L. J., Fry, W. E., Ritch, D. L., and Shelly, S. E. 1993. Nuclear DNA content, allozyme phenotypes and metalaxyl sensitivity of Phytophthora infestans from Japan. Mycol. Res. 97:945-950

50. Thurston, H. D. 1961. The relative survival ability of races of Phytophthora infestans in mixtures. Phytopathology 51:748-755. 
51. Tooley, P. W., and Fry, W. E. 1985. Field assessment of fitness of isolates of Phytophthora infestans. Phytopathology 75:982-988.

52. Tooley, P. W., Sweigard, J. A., and Fry, W. E. 1986. Fitness and virulence of Phytophthora infestans isolates from sexual and asexual populations. Phytopathology 76:1209-1212.

53. Tooley, P. W., and Therrien, C. D. 1987. Cytophotometric determination of the nuclear DNA content of 23 Mexican and 18 non-Mexican isolates of Phytophthora infestans. Exp. Mycol. 11:19-26.

54. Trout, C. L., and Ristaino, J. B. 1997. Fungicides affect mating behavior in Phytophthora infestans. (Abstr.) Phytopathology 87(suppl.):S98.

55. Vanderplank, J. E. 1982. Host-Pathogen Interactions in Plant Disease. Academic Press, New York.

56. Waggoner, P. E. 1952. Distribution of potato late blight around inoculum sources. Phytopathology 42:323-328. 